\title{
The Effects of Junior Florist Training Course on the Spatial Perception Ability and Hand Dexterity of Low-Income Children of Local Child Center
}

\author{
Young Hwa Park, Suk Young Yun*, Byung Jin Choi, and Hyun Sug Choi \\ Department of Horticulture, Daegu Catholic University, Gyeongsan 38430, South Korea
}

\begin{abstract}
The purpose of this study was to look into the influence of the junior florist training course on spatial perception ability and hand dexterity of low-income children at a community child center. For this purpose, 46 elementary school children who were divided into two groups attended total 13 sessions of program from June 2 to August 30 in 2017. In case of spatial perception ability, the control group did show any change $(p=.251)$, whereas the experimental group showed a significant progress $(p=.001)$. In case of hand dexterity, the control group showed a significant change at a major hand $(p=.018)$, whereas the experimental group showed a significant change at both a major hand $(p=.009)$ and a non-major hand $(p=.001)$. Looking into the differences on gender, both male participants $(p=.008)$ and female participants $(p=.040)$ showed a significant change in spatial perception ability, and in case of promptness, there was a significant change in male participants' major hand ( $p=.017$ ), and female participants' major hand ( $p=.044)$ and non-major hand $(p=.037)$. In the comparison between low grade children and high grade children, the lower graders showed significant changes in their spatial perception ability $(p=.001)$ and hand dexterity in a non-major hand $(p=.012)$, whereas high graders showed a significant change in hand dexterity in a non-major hand $(p=.042)$. In spatial perception ability, there was a more significant change in low graders than high graders, and in male children than female children.
\end{abstract}

Keywords: community child, major hand, non-major hand

\section{Introduction}

A family is the first social environment experienced by children as well as the first group in which personal relations are built. It is also responsible for raising and protecting children, and plays a crucial role in shaping their personalities physically, mentally and socially (Bloom, 1964). South Korea has shown great economic growth due to urbanization and industrialization, but broken families are increasing due to structural change of families as well as change of values and norms (Lee, 2003; Kim and An, 2005). Children from low-income families are psychologically unstable as their family circumstances are in poor economic state, and they are also weak in terms of scholastic achievement or behavioral development (Baik, 1996). Regional centers for children are mainly used by children from underprivileged and 
low-income families, and they are facilities aiming at providing comprehensive child welfare services to foster children in healthy conditions, including protection and education of children in the community, provision of sound play and recreations for them, and establishment of a linkage between their protectors and the community (Child Welfare Act, Article 52). Children using the centers are not properly cared due to their parents' low education level, economic poverty and family environment as well as broken home. Thus, they not only lack physical development but also have emotion internalization issues and cognitive growth problems such as low intelligence, academic slump and school dropout (Lee and Yoon, 2010).

In this circumstance, afterschool guidance is necessary for children, as well as an appropriate education program to fulfill emotional stability and guidance for individual children and help them develop soundly in light of emotional, social and physical aspects. Flower arrangement programs contributed to improving perceptivity, maintaining balance of whole body, using and improving human creativity and expressivity, and developing emotions by stimulating the five senses, and were proved effective in many previous studies for obsession, depression, anxiety, paranoia, anger management, concentration and accuracy of work (Lee et al., 1998; Tak, 2004; Lee at al., 2012; Son et al., 2013). Scissoring and using hands through various flower arranging techniques are also effective in recovering hand functions by promoting movements of hands and fingers (Ahn, 2007; Kim and So, 2011; Kim et al., 2017). The importance of spatial ability as a field of intelligence has been perceived as part of giftedness (Park, 2014). Space perception ability provides ways to interpret the physical environment in which we live and is developed as an important tool of problem solving. Korea is also aware of the importance of space sense and has organized elementary school mathematics in the 7th Curriculum in six fields, such as numbers and operations, measurements, figures, probability and statistics, words and equations, and patterns and functions, categorizing figures into plane, solid and space sense (Ministry of Education, 1998). This is aspect, activities using flowers are expected to produce the effect of emotional, physical and social education programs and contribute to standard academic ability and problem solving skills by improving space perception ability.

Therefore, this study provides a florist training course in which participants decorate and arrange flowers for various purposes for children from low-income families with poor academic achievement or behavioral development, and determines its effects on spatial perception ability and hand dexterity.

\section{Research Methods}

\section{Subject}

Subjects are elementary school students using regional centers for children in D city. The control group consists of 23 children who have not done any horticultural activities including flower arrangement, and the experimental group consists of 23 children that participated in the junior florist training course. Each group had 13 male and 10 female students, and 11 were in lower grades (first-third) and 12 were in higher grades (fourth-sixth). The two groups had the same number of students by gender and grade.

\section{Tools}

\section{Experimental design}

This study used the pretest-posttest nonequivalent design to examine the effects of the junior florist training course on children's space perception ability and dexterity. The perception ability and dexterity of the control group were measured 
before and after the program, and those of the experimental group were measured first before the program, and then again in the same way after they participated in the program. The control group did not participate in any activity, whereas the experimental group participated in horticultural activities applying 11 styles.

\section{Program design}

This study was conducted to examine the effects of the junior florist training course on children's space perception ability and dexterity. The program was in the basic form of Western flower arrangements in 11 styles focusing on linear, plane and stereoscopic styles. Books such as Easy-to-learn Flower Design (Kim et al., 2007) and Craftsman Floral Design Training (Jang and Noh, 2017) were used as a reference. Linear composition consisted of vertical style, horizontal style, L style, and crescent style; plane construction consisted of triangular style; and stereoscopic configuration consisted of spray style, dome style, round style, wreath, bouquets, flower baskets, as well as additional training of horticultural design theories (Table 1). Session 1 was dome style that provided the concept of symmetry, balance and hemisphere in terms of space concept, and Session 2 was wreath that provided the concept of circle, balance and asymmetry. Session 3 was horizontal style, which is a linear composition, and provided the concept of symmetry, balance, and ellipse. Session 4 was round style, which is a stereoscopic configuration, and provided the concept of symmetry, balance, circle and angular measure. Session 5 was L style, which is a linear composition, and provided the concept of asymmetry, imbalance and the right angle as angular measure.

Session 6 was bouquet, which is a stereoscopic configuration, and provided the concept of asymmetry, balance and spiral form. Session 7 was triangular style, which is a plan construction, and provided the concept of symmetry and balance by presenting the mathematical concept of triangles, and showed the characteristics of different types of triangles such as the right triangle, acute triangle and asymmetric triangles. Session 8 was vertical style, which is a linear composition, and provided the concept of asymmetry, balance and isosceles triangles. Session 9 was spray style, in which the bouquet was made as if placed on flower organ, and decorated with a ribbon. It provided the concept of symmetry, balance and triangles, and explained the basic structure of flowers. Session 10 was crescent style, which is a linear composition, and had the participants make curves by putting 20 floral wires in between horsetail plant, and provided the concept of asymmetry, imbalance and circles. Session 11 was flower basket, which is a stereoscopic configuration, and provided the concept of asymmetry, balance and circle. Session 12 was a comprehensive program of the entire course, having students arrange flowers in round style and spray style to prepare for practical examination. In Session 13, participants were to take the written and practical examination to get the junior florist certificate by Korea Flower Art Association.

\section{Program implementation}

This study was conducted once a week every Wednesday from June 7 to August 30, 2017 in a 39.6m² program room at the center using six rectangular tables, with the guidance of 1 main therapist holding the Welfare Horticultural Therapist certificate (Korean Horticultural Therapy Association) and three therapist assistants. The experimental group consisted of two teams, with 11 participants in Team A (grades 1-3) and 12 participants in Team B (grades 4-6). Total 13 sessions were carried out, with each session lasting 60 minutes. The program was carried out as follows. The style in the previous session was reviewed first, followed by an overview of that day's program as well as materials and style to be used in flower arrangement that day, and the mathematical concepts according to the style were introduced. Then, participants were to arrange flowers according to the order of that style, and wrapped up and made presentations of their thoughts for the day. 
Table 1. Training program for florist certification in the experimental group

\begin{tabular}{|c|c|c|c|c|}
\hline Session & Program & Space concept & Plants & Training content \\
\hline 1 & Dome style & $\begin{array}{l}\text { Stereo configuration, symmetry, } \\
\text { balance, hemisphere }\end{array}$ & $\begin{array}{l}\text { Rosa hybrida } \\
\text { Eustoma grandiflorum } \\
\text { Limonium latifolium } \\
\text { Asclepias tuberosa }\end{array}$ & $\begin{array}{l}\text { Floral form method, } \\
\text { Stem cutting }\end{array}$ \\
\hline 2 & Wreath & $\begin{array}{l}\text { Stereo configuration, asymmetry, } \\
\text { balance, circle }\end{array}$ & $\begin{array}{l}\text { Rosa hybrida } \\
\text { Oxypetalum caeruleum } \\
\text { Dianthus caryophyllus } \\
\text { Limonium sinuatum } \\
\text { Eustoma grandiflorum }\end{array}$ & $\begin{array}{l}\text { How to use the instrument to } \\
\text { remove the rose's thorn }\end{array}$ \\
\hline 3 & Horizontal style & $\begin{array}{l}\text { Linear composition, symmetry, } \\
\text { balance, ellipse }\end{array}$ & $\begin{array}{l}\text { Celosia cristata } \\
\text { Eustoma grandiflorum } \\
\text { Solidaster luteus } \\
\text { Callistephus chinensis }\end{array}$ & Organize materials \\
\hline 4 & Round style & $\begin{array}{l}\text { Stereo configuration, symmetry, balance, circle, } \\
\text { angular measure }\end{array}$ & $\begin{array}{l}\text { Rosa hybrida } \\
\text { Dianthus caryophyllus } \\
\text { Dianthus chinensis } \\
\text { Hypericum inodorum }\end{array}$ & $\begin{array}{l}\text { Watering } \\
\text { (Direct method) }\end{array}$ \\
\hline 5 & L style & $\begin{array}{l}\text { Linear composition, asymmetry, imbalance, } \\
\text { angular measure } \\
\left(90^{\circ}, 45^{\circ}\right)\end{array}$ & $\begin{array}{l}\text { Dianthus caryophyllus } \\
\text { Phormium tenax } \\
\text { Aster pilosus }\end{array}$ & $\begin{array}{l}\text { Line, form, mass, } \\
\text { filler flowers }\end{array}$ \\
\hline 6 & Bouquet & Stereo configuration, asymmetry, balance, spiral & $\begin{array}{l}\text { Rosa hybrida } \\
\text { Eustoma grandiflorum } \\
\text { Hypericum inodorum } \\
\text { Gypsophila elegans } \\
\text { Chrysanthemum morifolium }\end{array}$ & Spiral bouquet \\
\hline 7 & Triangular style & $\begin{array}{l}\text { Plane construction, symmetry, balance, triangular, } \\
\text { angular measure (an acute angle, a right angle) }\end{array}$ & $\begin{array}{l}\text { Phlox divaricata } \\
\text { Rosa hybrida } \\
\text { Chrysanthemum morifolium } \\
\text { Limonium sinuatum }\end{array}$ & Stem \\
\hline 8 & Vertical style & $\begin{array}{l}\text { Linear composition, asymmetry, } \\
\text { balance, triangular }\end{array}$ & $\begin{array}{l}\text { Gladiolus grandavensis } \\
\text { Eustoma grandiflorum } \\
\text { Aster tataricus }\end{array}$ & Drying method \\
\hline 9 & Spray style & $\begin{array}{l}\text { Stereo configuration, symmetry, balance, } \\
\text { triangular }\end{array}$ & $\begin{array}{l}\text { Rosa hybrida } \\
\text { Gypsophila elegans }\end{array}$ & The basic structure of a flower \\
\hline 10 & Crescent style & $\begin{array}{l}\text { Linear composition, asymmetry, imbalance, } \\
\text { circle, golden ratio }\end{array}$ & $\begin{array}{l}\text { Equisetum hyemale } \\
\text { Rosa hybrida } \\
\text { Eustoma grandiflorum } \\
\text { Solidaster luteus }\end{array}$ & Types and uses of wire \\
\hline 11 & Flower basket & Stereo configuration, asymmetry, balance, circle & $\begin{array}{l}\text { Rosa hybrida } \\
\text { Gentiana scabra } \\
\text { Aster spp. } \\
\text { Euphorbia marginata }\end{array}$ & Principle of consolidation \\
\hline 12 & \multicolumn{2}{|c|}{$\begin{array}{l}\text { Practical test preparation : } \\
\text { Dome style, spray style }\end{array}$} & $\begin{array}{l}\text { Rosa hybrida } \\
\text { Gentiana scabra } \\
\text { Gomphrena globosa } \\
\text { Solidaster luteus }\end{array}$ & \\
\hline 13 & \multicolumn{4}{|c|}{ Take a florist certificate examination } \\
\hline
\end{tabular}

\section{Evaluation tool}

\section{- Spatial perception ability test}

The spatial perception ability test developed by Choi (2004) was used to determine the effects of the junior florist course on the space perception ability of children at the center. This scale consists of 20 items in six categories such as two-dimensional rotation, three-dimensional rotation, reflection, finding stereoscopic form, number of blocks, and 
guessing figures with patterns. The reliability Cronbach's $\alpha$ was .68 (Choi, 2004), and the reliability Cronbach's $\alpha$ in this study was .76.

\section{- Sensory-motor coordination evaluation tool}

To examine dexterity, this study used the sensory-motor coordination evaluation tool called Grooved Pegboard (Lafayette, USA). It measures the time spent to put all 25 pegs into holes in irregular directions. The pegboard was placed at the center of the subject, and first measured the major hand followed by non-major hand. The right-handers go from left to right, holding only one peg at a time using just one hand. The left-handers go from right to left, performing the test in the same way as the right-handers.

\section{Results and Discussion}

\section{Test of normality}

To examine whether the collected data of the control group and experimental group follow normal distribution, a test was conducted using Kolmogorov-Smirnov and proved that for the control group, space perception ability $(p=.709)$, dexterity of major hand $(p=.666)$, and dexterity of non-major hand $(p=.794)$ showed normal distribution. As for the experimental group, all items such as space perception ability ( $p=.932)$, dexterity of major hand ( $p=.898)$, and non-major hand ( $p=.789$ ) also showed normal distribution (Table 2). Accordingly, parameters were tested for analysis of collected data in this study.

\section{Intergroup pretest homogeneity test}

To examine the homogeneity of the two groups before the program, an independent samples t test was conducted on measures of space perception ability and dexterity of major hand and non-major hand. For space perception ability, the control group was 60.2 points and the experimental group was 60.5 points, not showing a significant difference $(p=.941)$. For dexterity of major hand, the control group was 54.0 seconds and the experimental group was 53.6 seconds, not showing a significant difference ( $p=.826$ ), and for dexterity of non-major hand, the control group was 64.3 seconds and the experimental group was 64.6 seconds, also not showing a significant difference $(p=.869)$. In other words, there was no significant difference in all items of evaluation, and therefore the two groups can be regarded as homogeneous (Table 3 ).

Table 2. Normality test of collected data

\begin{tabular}{|c|c|c|c|c|c|c|c|}
\hline Group & & & Unit & $\mathrm{n}$ & M & $\mathrm{SD}$ & $p$ \\
\hline \multirow{3}{*}{ Control } & \multicolumn{2}{|c|}{ Spatial perception ability } & Score & 23 & 60.1 & 17.0 & $.709^{\mathrm{NS}}$ \\
\hline & \multirow{2}{*}{ Hand dexterity } & Major hand & Second & 23 & 54.0 & 6.2 & $.666^{\mathrm{NS}}$ \\
\hline & & Non-major hand & Second & 23 & 64.3 & 7.7 & $.794^{\mathrm{NS}}$ \\
\hline \multirow{3}{*}{ Experimental } & \multicolumn{2}{|c|}{ Spatial perception ability } & Score & 23 & 60.5 & 18.1 & $.932^{\mathrm{NS}}$ \\
\hline & \multirow{2}{*}{ Hand dexterity } & Major hand & Second & 23 & 53.6 & 6.3 & $.898^{\mathrm{NS}}$ \\
\hline & & Non-major hand & Second & 23 & 64.6 & 7.9 & $.789^{\mathrm{NS}}$ \\
\hline
\end{tabular}

${ }^{\mathrm{NS}}$ Non-significant at $p<.05$ by Kolmogorov-Smirnov test. 
Table 3. Pre-homogeneity test of control and experimental group

\begin{tabular}{|c|c|c|c|c|c|c|c|}
\hline \multirow{2}{*}{ Item } & & \multirow{2}{*}{ Unit } & \multicolumn{2}{|c|}{ Control } & \multicolumn{2}{|c|}{ Experimental } & \multirow[b]{2}{*}{$p$} \\
\hline & & & $\mathrm{M}$ & $\mathrm{SD}$ & M & $\mathrm{SD}$ & \\
\hline Spatial perceptic & & Score & 60.2 & 16.9 & 60.5 & 18.1 & $.941^{\mathrm{NS}}$ \\
\hline \multirow{2}{*}{ Hand dexterity } & Major hand & Second & 54.0 & 6.2 & 53.6 & 6.3 & $.826^{\mathrm{NS}}$ \\
\hline & Non-major hand & Second & 64.3 & 7.7 & 64.6 & 7.9 & $.869^{\mathrm{NS}}$ \\
\hline
\end{tabular}

${ }^{\mathrm{NS}}$ Non-significant at $p<.05$ by independent t-test.

Table 4. The effect of junior florist training course on spatial perception ability of subjects

(Unit: Score)

\begin{tabular}{lccccc}
\hline \multirow{2}{*}{ Group } & \multicolumn{2}{c}{ Pre-test } & \multicolumn{2}{c}{ Post-test } & $p$ \\
\hline Control & M & SD & M & SD & \\
Experimental & 60.2 & 16.9 & 60.5 & 16.5 & $.251^{\text {NS }}$ \\
\hline
\end{tabular}

${ }^{\mathrm{NS}}$ Non-significant, significant at ${ }^{* *} p<.01$ by paired t-test.

\section{Within-group pretest and posttest design}

\section{Changes in spatial perception ability}

Table 4 shows the result of analyzing changes in space perception ability of the control group and experimental group after the junior florist training course. The control group did not show a significant change from 60.2 to 60.5 after the program $(p=.251)$, but the experimental group that participated in flower arrangement showed a significant result from 60.5 to 69.4 after the program $(p=.001)$. Consistent with the previous study that spatial visualization ability, which perceives and rotates a specific figure, was improved as the participants went on with the program (Cho and Chong, 2012), this study also showed improvement in space perception ability by expressing geometrical forms using various flowers.

\section{Changes in dexterity}

Dexterity is measuring the time to put all 25 pegs into a grooved pegboard in irregular directions, and dexterity is considered to have improved if the time is reduced. The result of the control group showed that major hand did not show a significant change from 54.0 seconds to 54.1 seconds $(p=.573)$, and non-major hand showed a significant change from 64.3 seconds to 63.9 seconds ( $p=.018$ ). As for the experimental group, major hand showed a significant decrease from 53.6 seconds to 51.2 seconds after the program ( $p=.009)$, and non-major hand also showed a significant difference from 64.7 seconds to 60.7 seconds $(p=.001)$ (Table 5).

This is consistent with the results of previous studies that hand functions of persons with intellectual disabilities improved after repeated floral design programs (Kim and So, 2011), and that hand grip improved as a result of horticultural activities by persons with physical disabilities in a communal living facility (Ann, 2007). This study also proved that cutting flowers with scissors or putting flowers in increases eye-hand coordination and dexterity by using both hands.

\section{Comparison of the experimental group by gender}

By gender, male participants showed a significant change in space perception ability from 59.2 points to 66.6 points after the program $(p=.008)$, and female participants also showed a significant change from 62.3 points to 73.1 points 
Table 5. The effect of junior florist training course on hand dexterity of subject

(Unit: Second)

\begin{tabular}{lcccccc}
\hline \multirow{2}{*}{ Group } & \multirow{2}{*}{ Item } & \multicolumn{2}{c}{ Pre-test } & \multicolumn{2}{c}{ Post-test } & \multirow{2}{*}{$p$} \\
\hline \multirow{2}{*}{ Control } & M & SD & M & SD & \\
& Major hand & 54.0 & 6.2 & 54.1 & 6.1 & $.573^{\text {NS }}$ \\
\multirow{2}{*}{ Experimental } & Non-major hand & 64.3 & 7.7 & 63.9 & 7.5 & $.018^{*}$ \\
& Major hand & 53.6 & 6.3 & 51.2 & 5.3 & $.009^{* * *}$ \\
& Non-major hand & 64.7 & 7.9 & 60.7 & 7.8 & $.001^{* * *}$ \\
\hline
\end{tabular}

${ }^{\mathrm{NS}}$ Non-significant, significant at ${ }^{*} p<.05,{ }^{* *} p<.01$ by paired t-test.

Table 6. Changes in pre and post result by gender of the experimental group

\begin{tabular}{|c|c|c|c|c|c|c|c|c|}
\hline \multirow{2}{*}{ Group } & \multirow{2}{*}{\multicolumn{2}{|c|}{ Item }} & \multirow{2}{*}{ Unit } & \multicolumn{2}{|c|}{ Pre-test } & \multicolumn{2}{|c|}{ Post-test } & \multirow{2}{*}{$p$} \\
\hline & & & & M & SD & M & SD & \\
\hline \multirow{3}{*}{ Male } & \multicolumn{2}{|c|}{ Spatial perception ability } & Score & 59.2 & 17.6 & 66.6 & 18.7 & $.008^{* *}$ \\
\hline & \multirow{2}{*}{ Hand dexterity } & Major hand & Second & 54.6 & 7.8 & 52.2 & 6.3 & $.088^{\mathrm{NS}}$ \\
\hline & & Non-major hand & Second & 65.6 & 9.9 & 61.7 & 9.6 & $.017^{*}$ \\
\hline \multirow{3}{*}{ Female } & \multicolumn{2}{|c|}{ Spatial perception ability } & Score & 62.3 & 19.4 & 73.1 & 15.0 & $.040^{*}$ \\
\hline & \multirow{2}{*}{ Hand dexterity } & Major hand & Second & 52.2 & 3.6 & 49.8 & 3.6 & $.044^{*}$ \\
\hline & & Non-major hand & Second & 63.4 & 4.6 & 59.4 & 4.8 & $.037^{*}$ \\
\hline
\end{tabular}

${ }^{\mathrm{NS}}$ Non-significant, significant at ${ }^{*} p<.05,{ }^{* *} p<.01$ by paired t-test.

( $p=.040$ ), proving that both male and female participants showed a significant change in space perception ability. As for dexterity, male participants showed a significant change in non-major hand from 65.6 seconds to 61.7 seconds after the program $(p=.017)$, whereas female participants showed a significant change in both hands: major hand $(p=.044)$, non-major hand ( $p=.037$ ) (Table 6).

Gender differences in some cases follow the argument of the left-brain-right brain theory, which claims that the left brain (language) and right brain (spatial ability) are involved in different things depending on their functions, and women have their left brains and men have their right brains developed relatively more than the other (Kwon et al., 1996; Choi, 2004). There are various causes and results according to spatial ability and gender differences, but recently the gender differences tended to decrease and there are some parts of spatial ability in which either women or men are better, and thus female-friendly ability and male-friendly ability are separated (Anstett, 2000).

\section{Comparison of the experimental group by grade}

Table 7 shows the changes in space perception ability and dexterity of the experimental group by dividing them into lower grades and higher grades. The lower grades showed a significant change in space perception ability from 50.7 points to 64.1 points after the program ( $p=.001$ ), and also in dexterity of non-major hand from 68.3 seconds to 63.1 seconds ( $p=.012$ ). The higher grades showed a significant change in dexterity of non-major hand from 61.3 to $58.5(p=.042)$. Unlike the result of the study that natural cognitive development and more learning experience had a greater effect on spatial ability (Cho and Chong, 2012), the lower grades showed more significant results than higher grades in this study. Consistent with the result that the lower grades show better learning effects and the gap is reduced as their grades go up 
Table 7. Changes in pre and post result by grade of the experimental group

\begin{tabular}{|c|c|c|c|c|c|c|c|c|}
\hline \multirow{2}{*}{ Group } & \multirow{2}{*}{\multicolumn{2}{|c|}{ Item }} & \multirow{2}{*}{ Unit } & \multicolumn{2}{|c|}{ Pre-test } & \multicolumn{2}{|c|}{ Post-test } & \multirow{2}{*}{$p$} \\
\hline & & & & M & SD & M & SD & \\
\hline \multirow{3}{*}{ Low } & \multicolumn{2}{|c|}{ Spatial perception ability } & Score & 50.7 & 12.7 & 64.1 & 18.2 & $.001^{* * *}$ \\
\hline & \multirow{2}{*}{ Hand dexterity } & Major hand & Second & 55.7 & 4.6 & 53.3 & 4.9 & $.082^{\mathrm{NS}}$ \\
\hline & & Non-major hand & Second & 68.3 & 6.8 & 63.1 & 8.3 & $.012^{*}$ \\
\hline \multirow{3}{*}{ High } & \multicolumn{2}{|c|}{ Spatial perception ability } & Score & 69.6 & 17.9 & 74.3 & 15.2 & $.155^{\mathrm{NS}}$ \\
\hline & \multirow{2}{*}{ Hand dexterity } & Major hand & Second & 51.6 & 7.2 & 49.2 & 5.1 & $.066^{\mathrm{NS}}$ \\
\hline & & Non-major hand & Second & 61.3 & 7.7 & 58.5 & 7.0 & $.042^{*}$ \\
\hline
\end{tabular}

${ }^{\mathrm{NS}}$ Non-significant, significant at ${ }^{*} p<.05,{ }^{* *} p<.01,{ }^{* * *} p<.001$ by paired t-test.

(Kwon et al., 1996), the lower grades may have shown better effect on space perception ability as they have good learning attitude and enthusiastically accepts what their teachers say, even though they lack general experience in learning.

\section{Conclusion}

To examine the effects of the junior florist training course on the space perception ability and dexterity of children using regional centers for children, this study conducted total 12 sessions of the program from June 2 to August 30, 2017 on 46 children using a regional center for children in $\mathrm{D}$ city, dividing them into two groups for comparison. For space perception ability, the control group did not show any change $(p=.251)$, but the experimental group showed a significant improvement ( $p=.001$ ). For dexterity, the control group showed a significant change in major hand ( $p=.018$ ), and the experimental group showed a significant change in both major hand $(p=.009)$ and non-major hand $(p=.001)$.

By gender, both male $(p=.008)$ and female $(p=.040)$ participants showed a significant change in spatial perception ability. For dexterity, male participants showed a significant change in non-major hand ( $p=.017)$, and female participants in both major hand $(p=.044)$ and non-major hand ( $p=.037)$. In comparing lower and higher grades, the lower grades showed a significant change in space perception ability $(p=.001)$, dexterity of non-major hand $(p=.012)$, whereas the higher grades showed a significant change in dexterity of non-major hand $(p=.042)$. As for space perception ability, the lower grades showed a more significant change than the higher grades, and female than male participants.

\section{References}

Ahn, J.Y. 2007. Effect of horticultural therapy on hand function and quality of life of the crippled disordered persons in the group home. Master's thesis, Daegu Catholic University, Daegu, Korea.

Anstett, P. 2000. What each gender finds easy to learn. Detroit Free Press. Retrieved from http://www.freep.com

Baik, J.J. 1996. The relation between the psychological environment of family and mal-adaption behavior that perceived by the children of low-income family. Master's thesis, Sookmyung Women's University, Seoul, Korea.

Bloom, B.S. 1964. Stability and change in human characteristics. New York, USA: Wiley.

Cho, Y.S. and Y.O. Chong. 2012. A survey on the spatial sense ability of elementary school students -Focusing on fourth to sixth graders-. J. Elementary Math. Educ. Korea 16(3):359-388.

Choi, M.Y. 2004. Study on gender differences in elementary school children's spatial ability. Master's thesis, Korea National University of Education, Chung-Buk, Korea. 
Jang, E.O. and S.B. Noh. 2017. Craftsman floral design: Actual. Seoul, Korea: Soopool Media.

Kim, J.H., J.Y. Kim, and S.J. Ahn. 2007. Easily learn flower design. Seoul, Korea: Flowernews.

Kim, K.S. and I.S. So. 2011. The effect of the horticultural therapy using repetitive floricultural decoration program on the improvement in work performance and hand skills of the intellectually handicapped. J. Asian Agriculture and Biotechnology 27(1):27 37.

Kim, Y.H., S.Y. Yun, and B.J. Choi. 2017. The effect of the floral arrangement in a designed space specified on the visual perception motor coordination capability ability and hand function of the with dementia elderly. J. People Plants Environ. 21(3):213-221.

Kim, Y.R. and M.J. An. 2005. A comparative study on the difference of gender-role identity and self-esteem between children of broken homes and those of normal homes. J. Hum. Underst. Couns. 26:105-124.

Kwon, O.N., K.M. Park, H. Im, and R.G. Huh. 1996. A study on gender difference in spatial ability. J. Korean Soc. Math. Educ. Ser. A: Math. Educ. 35(2):125-141.

Lee, E.G. 2003. Emotional \& behavioral problems in children from broken family. Master's thesis, Ewha Womans University, Seoul, Korea.

Lee, H.W. and H.M. Yoon. 2010. Exploring child advocacy in Korea: Focused on the victims of child abuse and neglect. J. Sch. Soc. Work 18:107-127.

Lee, J.M., K.C. Son, and E.H. Koh. 1998. Practical application of flower \& art design as horticultural therapy. Proceedings of first symposium of korean horticultural therapy association. Seoul, Korea: Seowon Press.

Lee, S.S., S.A. Park, O.Y. Kwon, J.E. Song, and K.C. Son. 2012. Measuring range of motion and muscle activation of flower arrangement tasks and application for improving upper limb function. Korean. J. Hortic. Sci. Technol. 30(4):449-462.

Ministry of Education. 1998. Explanation of elementary school curriculum(IV): Mathematics, science, a practical course. Sejong, Korea.

Park, G.C. 2014. The effect of a collage-applied art education program on the hand function of children with intellectual disability. Master's thesis, Busan University, Busan, Korea.

Son, M.L., E.J. Jang, and C.H. Pak. 2013. Effect of flower decoration horticulture program on emotional stabilization and stress of woman high school students. J. People Plants Environ. 16(3):119-124.

Tak, Y.S. 2004. The effect of horticultural therapy using the flower arrangement in center: Terminal cancer patients. Master's thesis, Honam University, Gwangju, Korea. 